\title{
Peter Nynäs, Mika Lassander, Terhi Utriainen (Eds.), Post-Secular Society
}

New Brunswick, NJ, Transaction editors, 2012, 282 p.

\section{Mira Niculescu}

\section{(2) OpenEdition}

\section{Journals}

Édition électronique

URL : http://journals.openedition.org/assr/25572

DOI : $10.4000 /$ assr. 25572

ISSN : $1777-5825$

\section{Éditeur}

Éditions de l'EHESS

Édition imprimée

Date de publication : 30 décembre 2013

Pagination : 257

ISSN : 0335-5985

Référence électronique

Mira Niculescu, «Peter Nynäs, Mika Lassander, Terhi Utriainen (Eds.), Post-Secular Society », Archives de sciences sociales des religions [En ligne], 164 | 2013, mis en ligne le 12 mars 2014, consulté le 21 septembre 2020. URL : http://journals.openedition.org/assr/25572 ; DOI : https://doi.org/10.4000/ assr.25572

Ce document a été généré automatiquement le 21 septembre 2020.

(C) Archives de sciences sociales des religions 


\section{Peter Nynäs, Mika Lassander, Terhi Utriainen (Eds.), Post-Secular Society}

New Brunswick, NJ, Transaction editors, 2012, 282 p.

Mira Niculescu

RÉFÉRENCE

Peter Nynäs, Mika Lassander, Terhi Utriainen (Eds.), Post-Secular Society, New Brunswick, NJ, Transaction editors, 2012, $282 \mathrm{p}$. 
1 Post-Secular society est un ouvrage collectif coédité par Peter Nynäs, professeur de religion comparée, Mika Lassander, postdoctorant penché sur le rapport entre valeurs et changement religieux, tous deux de l'Université Äbo Akademi à Tulku, et Terhi Utriainen professeur de religion et "gender studies" à l'Université d'Helsinki. Cet ouvrage s'inscrit dans le sillage d'une production académique finlandaise très dynamique depuis plusieurs années - au point que l'on peut se demander si l'on ne serait pas en train d'assister à l'émergence d'une "école finlandaise » focalisée sur les renouvellements contemporains des rapports au croire, au corps et à leur gouvernance, dans des sociétés occidentales régies par le néo-libéralisme,

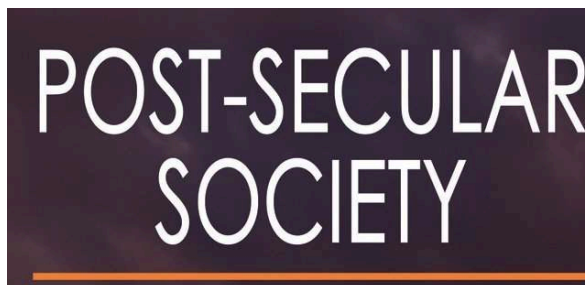

Peter Nynäs, Mika Lassander, and Terhi Utriainen editors

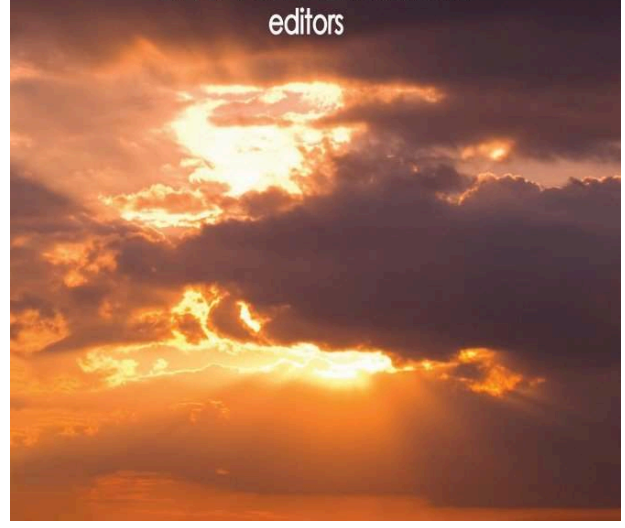
la globalisation et la culture médiatique.

2 Dans cette veine, Post-Secular Society a pour double objet à la fois d'offrir une réflexion théorique sur la notion de religieux "postséculier», et de dresser un portrait multifacette des formes que prend ce paradigme dans les sous-cultures concrètes qui traversent les sociétés occidentales contemporaines.

3 À la suite des réflexions d'Habermas, l'ouvrage prend pour paradigme dominant le concept de "postsécularité » comme nouvelle analytique du contexte culturel actuel des sociétés occidentales «postmodernes». En effet, entre les renouveaux fondamentalistes et les développements des "spiritualités » du bien-être, les thèses d'une sécularisation " totale » et définitive des sociétés occidentales comme compagne inévitable de leur modernisation apparaissent incontestablement dépassées. $\mathrm{Ni}$ totalement areligieuses, comme le prédisaient les sociologues dans les années 1960, ni totalement inondées par les revivalismes religieux récents dont l'impact est augmenté par les dynamiques de la globalisation et des réseaux virtuels, comment décrire la place du religieux dans les cultures occidentales actuelles?

4 La postsécularité est décrite par Habermas comme une « conscience publique accrue du religieux ", visible à travers trois phénomènes sociaux particuliers : l'immigration, les conflits globaux et les débats socio-politiques nationaux.

5 Les auteurs de cet ouvrage, tout en se basant sur cette prémisse, voient deux faiblesses dans la théorie habermassienne: d'une part, le manque de support empirique d'une vision trop «intellectualisée et rationaliste» de la religion, d'autre part, une description impuissante à rendre compte des tensions créées par le paradoxe entre une idéologie de la pluralité des discours croyants et celle d'un langage universel qui permette la communication et la cohabitation pacifique entre ces différents discours.

6 L'ambition de Post-Secular Society est donc d'offrir une gamme conceptuelle apte à décrire la situation postséculière contemporaine tout en s'extirpant de ce qui est considéré comme l'aporie de la théorisation habermassienne. 
7 Le point de départ reste le constat général d'un socle culturel séculier des sociétés occidentales contemporaines, pour mieux accentuer la dimension concomitante de «contre-développements dans des formes postinstitutionnelles de religion et de spiritualité ».

8 Ainsi, dans son article d'ouverture, à la suite de Charles Taylor (A Secular Age, The Belknap Press of Harvard University Press, 2007), José Casanova qualifie le paradigme culturel séculier qui sert de toile de fond aux dynamiques religieuses " postséculières " actuelles, d'«expérience phénoménologique axiomatique». Cette expérience serait celle d'une immanence culturelle procurant une autonomie sémantique aux trois ordres présidant à l'expérience humaine : cosmique, scientifique et morale.

9 Le langage de cette immanence axiologique, semblent argumenter les différents contributeurs, est celui du néolibéralisme; son échelle, le transnationalisme, et son vecteur, la culture médiatique. Ainsi pour deux autres contributeurs, Moberg et Granholm, la religion devient partie intégrante d'un nexus qui la conjugue avec trois autres domaines appartenant a priori au domaine purement séculier: les médias, la culture populaire (Popular Culture), et la culture de la consommation (Consumer Culture).

10 Ce nouveau paradigme serait notamment caractérisé par le déclin des religions et identités nationales, au profit de dynamiques séculières, transnationales et d'hybridité du croire et de ses pratiques. C'est ce que souligne Tuomas Martikainen dans son article sur les métamorphoses des acteurs religieux d'une part, et de leur gouvernance étatique d'autre part, dans un contexte néolibéral ou la présence accrue des médias engendre un nouveau «marketing religieux»: appelant à une réflexivité terminologique, le sociologue finlandais suggère que les termes de " société », « d'Étatnation» et de «religion» appartiennent autant à un paradigme "moderne " aujourd'hui dépassé, que ceux de «capital social», "gouvernance» et « transnationalisme » semblent relever de notre ère.

11 De son côté, Lassander propose une déconstruction de l'objet "religion » au profit d'une vision dynamique et contextuelle, sur le modèle Latourien des théories « acteur réseau ». Cette nouvelle posture théorique est selon lui un produit de la "modernité liquide » tel que la décrit Zygmunt Baumann.

12 Le champ lexical de la fluidité marqué, comme ceux de "postmodernité » et "postsécularité ", par la perméabilité des frontières et la circulation entre les différentes catégories sociales, représente donc l'orientation théorique générale de Post-Secular Society. Pour Lassander, comme pour les autres contributeurs, il dicte la fin d'une conception essentialiste des «religions mondiales» au profit de l'approche intersubjective d'une "religion vernaculaire» ou «vécue», penchée sur les expériences et les constructions de sens individuelles.

13 L'appel à la prise en compte des idéologies au principe des théorisations académiques semble être un enjeu épistémologique récurrent dans Post-Secular Society: dans leur analyse des «nouvelles religiosités non institutionnelles ", qu'ils préfèrent au terme " New Age " et à toute catégorisation "religieuse » essentialiste en général - qu'ils estiment obsolète dans le contexte de globalisation actuelle - Frisk et Nynäs appellent à la "réflexivité conceptuelle » et à la "sensibilité éthique». Tout en se basant très largement sur les travaux de Heelas et Woodhead sur la «révolution spirituelle occidentale» contemporaine, ils critiquent une thèse de «subjectivisation du religieux », qu'ils estiment justement « chargée de jugement subjectif ». Pourtant, leur 
typologie des «processus interconnectés du changement religieux contemporain liés à la globalisation ", est très fortement basée sur cette même idée d'individualisation du croire. Au point d'affirmer que "l'individu peut sélectionner selon son choix personnel » ou que « les éléments » empruntés au religieux «migrent librement avec comme seule limite le choix individuel ». Alors même que ses auteurs appellent à la distance idéologique, une telle perspective ultraindividualiste paraît fortement affinitaire avec l'idéologie néo-libérale. Surtout, elle semble trop optimiste, ignorant les appels à la prudence face à l'illusion de choix croyants "absolus ", sans préconditions culturelles ni contraintes sociales (Danièle Hervieu-Léger, _ «Bricolage vaut-il dissémination? Quelques réflexions sur l'opérationnalité sociologique d'une métaphore problématique », Social Compass, 52-3, 2005, p. 295-308; André Mary, «En finir avec le bricolage... ? », ASSR, 116, 2001, p. 27-30).

Un autre piège dans les tentatives de distinction théorique est celui des tentatives d'innovation conceptuelle «à tout prix ». Cela peut aboutir à simplement choisir de nouveaux mots pour des concepts préexistants. L'on pourrait considérer que c'est le cas de la notion d'« innovationisme » proposée par Katja Valaskivi : la définition qu'offre l'auteur de ce qu'elle estime être un nouveau « système de croyances intramondain » assimilant au passage les notions de "croire » et de "religieux" au point d'estimer que l'on peut considérer "l'innovationisme comme religieux »- correspond très exactement à l'éthique de la modernité, que l'on est précisément censés avoir dépassée dans un contexte post-moderne.

Ces discussions ont cependant le mérite de s'atteler à la question de la définition de la « religion », exercice auquel beaucoup de sociologues semblent avoir renoncé en vertu de l'insaisissabilité de son objet. Au contraire, tout au long de ses contributions, PostSecular Society offre des exercices de redéfinition et des re-conceptualisation du croire contemporain. Ainsi, dans leur réflexion sur la relation entre choix et agentivité dans les « pratiques du bien-être » contemporain, Utriainen, Hovi et Broo reviennent sur la définition de concepts comme "religion vécue » et "pratique " pour examiner les parallèles, superpositions et tensions existant entre pratiques "spirituelles" et scientifiques dans le champ de la guérison.

Le souci commun de la plupart de ces chercheurs du postséculier semble donc être de trouver des signes de religiosité dans des formes sociales a priori areligieuses - y compris, par exemple, chez les membres non pratiquants de groupes religioidentitaires : ainsi Pessi et Jeldtoft se penchent sur « le rôle que joue la religion » chez des individus "passifs", non impliqués dans leur groupe religieux d'appartenance. Dans toutes ces approches du religieux dans les interstices du religieux institutionnel traditionnel, on peut regretter alors de ne pas voir citer des auteurs comme Albert Piette qui a abordé ces questions du "mode mineur» du religieux dans les vies quotidiennes. Il reste que seule la contribution de Pessi et Jeldtoft, en concluant que « les vies religieuses individuelles ne sont pas aussi individualistes » qu'on a tendance à le supposer, tempère le sens d'une indépendance absolue des religiosités individuelles qui ressort de l'ensemble de l'ouvrage. 